\title{
Efficacy of asthma education program on asthma control in children with uncontrolled asthma
}

\author{
Zeynep Arıkan-Ayyıldız', Sakine $\mathrm{Işık}^{2}$, Şule Çağlayan-Sözmen², Özden Anal², \\ Özkan Karaman², Nevin Uzuner ${ }^{2}$ \\ ${ }^{1}$ Gazi Yaşargil Training and Research Hospital, Diyarbakır, ${ }^{2}$ Division of Pediatric Allergy and Immunology, Dokuz Eylül \\ University Faculty of Medicine, Izmir, Turkey. \\ E-mail: zarikanayyildiz@gmail.com \\ Received: 3rd March 2016, Revised: 26th October 2016, Accepted: 25th November 2016
}

SUMMARY: Arıkan-Ayyıldız Z, Işık S, Çağlayan-Sözmen Ş, Anal Ö, Karaman Ö, Uzuner N. Efficacy of asthma education program on asthma control in children with uncontrolled asthma. Turk J Pediatr 2016; 58: 383-388.

We aimed to evaluate the efficacy of a group education program on asthma control for children with uncontrolled asthma. Patients were randomized to receive 1-hour group education program with their parents or usual care. Our primary outcome was the change in asthma control test (ACT) between baseline and month 3 and secondary outcomes were health care utilizations and self report of exacerbations of asthma symptoms and missed school days. Change of ACT between baseline and 1st month and 3rd month was not significant in education and usual care groups. Health care utilizations and self reported exacerbations in the study groups were similar while missed school days were significantly higher in usual care group. The results of the study suggest that group education may play a useful role in the management of children with uncontrolled asthma but it is not significantly effective when compared with usual care.

Key words: education, uncontrolled asthma, children, intervention.

Asthma is the most common chronic disesase of childhood in developed countries and affects more than 150 million people all over the world ${ }^{1}$. All asthma guidelines published concerning adults or children emphasize the importance of asthma control in management of asthma1-3.

Asthma control has been reported to be poor in Turkey ${ }^{4,5}$. Emergency room visits and hospitalization rates are higher than those in EU countries ${ }^{4-6}$. There have been many studies about the role of asthma education on control of asthma in the world, but our national data is scarce ${ }^{7-9}$. There is a need for defining and creating an optimal education program for children with asthma in our country.

We report the results of a randomized trial to assess the effect of an educational intervention among children with poorly controlled asthma.

\section{Material and Methods}

We conducted a randomized prospective trial to evaluate the efficacy of asthma group education program on asthma control in children with uncontrolled asthma. The study was approved by the local ethical committe and all participants were given informed consent.

\section{Study population}

We recruited children aged 5-18 years with uncontrolled asthma from the Pediatric Allergy Unit of Dokuz Eylül University, Izmir. Recruitment occurred between December 2012May 2013. Asthma was diagnosed according to the GINA guidelines and poor control was defined as having asthma control test scores below 191. Patients who did not give informed consent, who had serious comorbidities and patients planning to move in the following months were excluded.

\section{Randomization and consent}

Eligible subjects were randomized to the group education program or usual care in equal groups. Blocks of varying sizes were 
used for randomization to assure the balance of randomization assignments over time. Informed consent was obtained from the parents of the children and from the children themselves above the age of 10 according to the instructions of local ethical committe. A total of 78 children were randomized into the study. Consort diagram of the study is shown in Figure 1.

\section{Intervention}

The study intervention consisted of 1 hour interactive class for at least 5 children and their parents taught by trained educator. The content of the class was based on the goals of the education program stated by guidelines which was revised for children and included information on the pathogenesis of asthma, enviromental triggers for asthma exacerbations, medications and how they act on disease, and how are the inhaled medications used. Videos

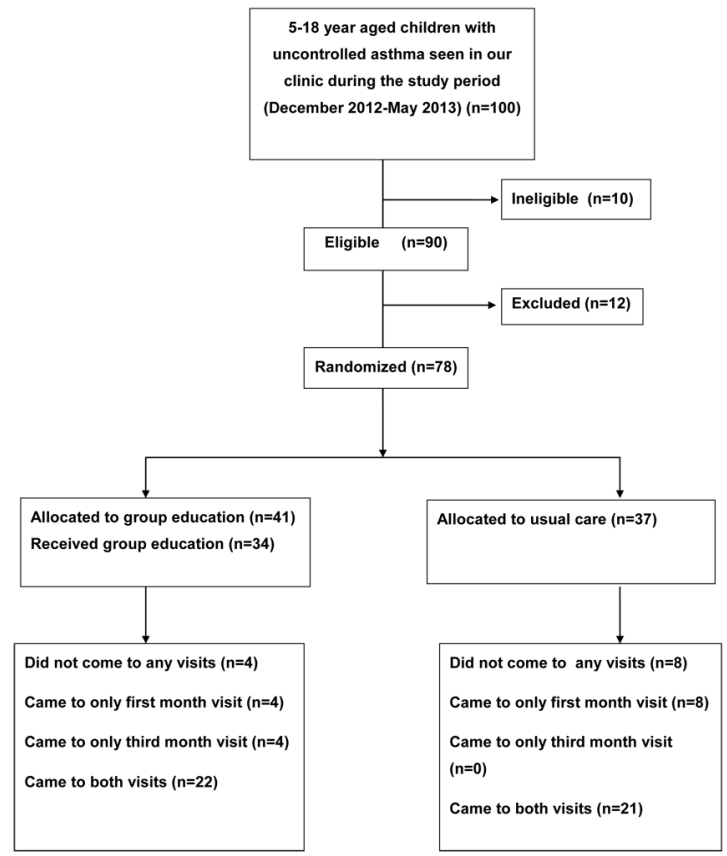

Fig. 1. Consort diagram of the study and visual presentations were used in group education. Individual questions and preventive measures were discussed at the end of each session. Usual care included demonstration of the use of inhaler devices and medication and prevention advices from the clinical nurse according to the atopic status of the individual patient.

Time to intervention ranged between 1-14 days post randomization and 7 of the 41 children assigned to the intervention did not attend the class.

\section{Measurements}

We administered questionnaires and assessed lung function at baseline (prior to randomization) and again at one month and 3 months following randomization. Baseline questionnaire including demographics and clinical data were filled out by the clinician. Baseline demographic data included age, sex, age at diagnosis, comorbid allergic diseases, presence of atopy determined by positive skin prick tests. Skin prick tests were performed by using a panel of aeroallergens (Allergopharma) including house dust mites, animal dander grass and cereal pollens, molds and tree pollens according to the EAACI guidelines ${ }^{10}$. Hospitalizations, self reported exacerbations, emergency room visits, unplanned hospital visits and missed school days were recorded by the physician at each visit.

We measured asthma control using the asthma control test (ACT), a standardized validated instrument that has been translated and validated for use in the Turkish language with children aged 4 and older ${ }^{11,12}$. Scores vary between 0-27 for the ACT of children aged 4-11 and 5-25 for the ACT of the children older than 12, with higher scores indicating better control and a score below 19 generally used to indicate uncontrolled asthma ${ }^{11,12}$. Asthma control tests were filled out by the children

Table I. Demographics of the Children with Uncontrolled Asthma Participating in the Study

\begin{tabular}{lcc}
\hline Variables & $\begin{array}{c}\text { Education } \\
(\mathrm{n}=26)\end{array}$ & $\begin{array}{c}\text { Usual care } \\
(\mathrm{n}=21)\end{array}$ \\
\hline Age $($ mean $\pm \mathrm{SD})$ & $10.1 \pm 2.7$ & $9.7 \pm 3$ \\
Female $(\%)$ & 50 & 47.6 \\
Age at diagnosis (mean $\pm \mathrm{SD})$ & $6.17 \pm 3.2$ & $6.3 \pm 3.3$ \\
ACT Baseline (mean $\pm \mathrm{SD})$ & $13.8 \pm 3.4$ & $15.6 \pm 3.2$ \\
\hline
\end{tabular}


aged older than 12 and by the child and the parent between ages 5-12. The change in ACT between baseline and month 3 served as our primary outcome and change from baseline to month 1 as a secondary outcome.

Additional secondary outcomes were health care utilizations including self reported hospital visits, emergency room visits and unscheduled hospitalizations and self report of exacerbations of asthma symptoms, and self-report of missed school days.

\section{Analysis}

The study was designed to have $80 \%$ power to detect a mean difference of 2 in ACT change between the groups assuming a standard deviation of change in ACT of 4 , a twotailed test, and a type 1 error rate of $5 \%$. All calculation were done in SPSS for Windows, version 15 Stata, Version 12.

Descriptive characteristics were shown as mean $\pm S D$, percentiles or median according to the type of the data. The change in ACT between baseline and months 1 and 3 was compared with linear regression model after adjusting the baseline ACT levels. Secondary outcomes were compared between groups using Chi-square and Mann-Whitney U test.

\section{Results}

Twenty six patients in the education group and 21 patients in the usual care group were included in the study. The mean age of the study population was $9 \pm 2.8,50 \%$ of the patients were female and the mean age of diagnosis was $6.3 \pm 3.2$ and all these variables were similar in both groups. (Table I).
Change of ACT between baseline and 1st month and 3rd month was not significant in education and usual care groups $(p=0.9)$ and this result was consistent in different age groups having different asthma control tests (Table II). The increase of ACT between baseline and first month was larger in educational group but this was not statistically significant (Table II, Fig. 2).

We assesed health care utilizations and self reported exacerbations in the study groups and the difference was not significant $(p=0.2$, $\mathrm{p}=0.5, \mathrm{p}=0.74, \mathrm{p}=0.2$ ) while missed school days were significantly higher in usual care group (Table III).

\section{Discussion}

In this randomized trial, we found that 1-hour educational intervention for children with uncontrolled asthma and their parents did not affect the asthma control assessed in the first and third months. Asthma control test scores tended to increase on the following months in both groups but scores at the first month in

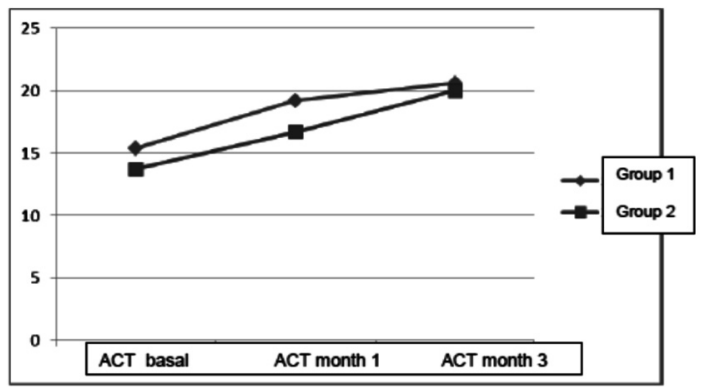

Fig. 2. Trends of ACT scores in two groups during the study period

(Group 1: Education, Group 2: Usual care)

Table II. Impact of Intervention on Asthma Control Adjusted for Baseline ACT

\begin{tabular}{|c|c|c|c|c|c|}
\hline \multirow[b]{2}{*}{ ACT } & \multicolumn{2}{|c|}{ Age 5-11 } & \multirow[b]{2}{*}{$\mathrm{p}$} & \multicolumn{2}{|c|}{ Age $>12$} \\
\hline & Education $(\mathrm{n}=17)$ & $\begin{array}{c}\text { Usual Care } \\
(\mathrm{n}=14)\end{array}$ & & $\begin{array}{l}\text { Education } \\
\quad(n=9)\end{array}$ & $\begin{array}{c}\text { Usual Care } \\
\quad(n=7)\end{array}$ \\
\hline $\begin{array}{l}\text { Baseline } \\
(\text { mean } \pm S D)\end{array}$ & $16.1 \pm 2.2$ & $13.7 \pm 3.9$ & & $14 \pm 4.1$ & $13.7 \pm 2.2$ \\
\hline $\begin{array}{l}\text { Change at the } \\
\text { 1st month }\end{array}$ & $3.5 \pm 3$ & $3.0 \pm 4.5$ & 0.2 & $3.4 \pm 3.9$ & $2.6 \pm 2.6$ \\
\hline $\begin{array}{l}\text { Change at the } \\
\text { 3rd month }\end{array}$ & $4.7 \pm 3.8$ & $6.1 \pm 3.8$ & 0.9 & $6 \pm 4.7$ & $6.4 \pm 3.7$ \\
\hline
\end{tabular}


Table III. Secondary Outcomes of the Study Population

\begin{tabular}{|c|c|c|c|}
\hline Secondary outcomes & Education $(n=26)$ & Usual care $(n=21)$ & $\mathrm{p}$ \\
\hline Health care utilization* & 23 & 28.5 & 0.74 \\
\hline Self-reported exacerbations* & 19.2 & 42.8 & 0.2 \\
\hline Missed school days ${ }^{¥}$ & $0.1 \pm 0.3$ & $2 \pm 4$ & 0.006 \\
\hline
\end{tabular}

* Expressed as (\%), ${ }^{*}$ Expressed as mean \pm SD

ACT: asthma control test

the education group increased more than usual care group although it was not statistically significant.

Education has a primary role in asthma management and the role of education has been assesed in asthma control in previous studies $^{13-18}$. Asthma education programs in these studies are different in their nature by means of population, intervention and duration. In general, education programs are aimed at asthmatic children or/and their caregivers. Education of caregivers help their control of home environment and their childrens'asthma signs and symptoms ${ }^{17}$. Asthmatic children whose caregivers underwent a targeted education were found to have fewer emergency department visits ${ }^{15}$. But there is also a study in the literature that indicates educational intervention is not beneficial when targeted to only caregivers ${ }^{14}$. Educational interventions also differ in the literature. There are educational programs for individual groups, group educations (asthma class, asthma camp etc.) and web based individual programs. Most of the studies report reductions in emergency department visits, hospitalizations and overall improvement of asthma control ${ }^{18,19}$. Studies evaluating the effects of education report benefit of education when they evaluate the outcomes on 6th months and 12th months ${ }^{14,16,18-19}$. We evaluated our outcome measurements 1 and 3 months after intervention. This period may be regarded as short for evaluation but the inconsistent improvement of asthma control test on 1 st and $3 \mathrm{rd}$ months may also be attributed to the patient group which have uncontrolled asthma.

Health care utilizations are one of the most important issues used in health economics and we chose health care utilizations as our secondary outcomes. Asthma control program in Brazil which included training of health professionals and educational interventions for the patients were found to reduce the number of asthma related hospital admissions ${ }^{20}$. Edcuation provided in school asthma class or in asthma day camp also yielded significant reductions in the emergency department and office visits ${ }^{19}$. We found that hospitalizations, emergency room admissions and unscheduled hospital visits were not different between groups but missed school days were significantly lower in education group. This result can be attributed to the increase of self-confidence and better coping with disease after group education program.

Uncontrolled asthma is found to be associated with low maternal education with strong beliefs about medication necessity and higher concern about potential side effects of medication ${ }^{21,22}$. Education programs are effective in asthma control because they change the behavior of the patients and caregivers on medication and help improvement of adherence, acute attack management and avoidance of triggers ${ }^{15-17,23-24}$. We think that the perception of disease and medication by child and parents changed with the educational intervention, however, we did not measure how the education affected and changed behavior in our study.

This study has some potential limitations. First of all, the time of the assesments were somewhat different because education was offered to patients after a mean period of 7 days after randomization but this was not the case in usual care group. And the second and most important limitation was the power of our study. We planned to include more patients but the sample size we could reach gave us only $40 \%$ power. We reached encouring results about the effects of education in our study but because of limited power, our study can be regarded as a pilot study.

We could not reach any significant differences by means of primary outcome in study groups. Usual care education may be sufficient enough 
to touch the routine life or the content of group education may be insufficient or too wide to concentrate for the attenders. Early timing of ACT measurements in each groups may also be the reason of this result as we discussed before.

Randomized trials are more reliable for demonstration of difference between two groups. But adherence to that kind of studies becomes a real life problem as realized in our study. Our sample size decreased because of the need of extra time for educational class. We think that the impact of usual care which is provided at the same time with the doctor visit can also be improved and educational interventions can be offered within the visit.

Although underpowered, the preliminary results of our study is promising for the positive effects of education on asthma control. In larger patient populations, it will be more clear to outline the short-term and long-term effects of the education and the need for the repetitive education programs could be more precisely defined.

\section{Acknowledgements}

This study was the project of MECOR (Methods in Epidemiological, Clinical and Operational Research) level 1 team (Zeynep Arıkan Ayyıldız (ZAA), Berrin Ceyhan, Ayşe Bilge Öztürk, Ebru Damadoğlu and Bilun Gemicioğlu) supervised by Tom Newman. It was planned as a multicenter study in pediatric and adult asthma centers but ZAA created the study in pediatric patients. The data and statistics of the work was presented by ZAA supervised by William M.Vollmer in MECOR level 3, Cesme, 2014. We thank very much to all contributors and MECOR faculty members of Turkish Thoracic Society and American Thoracic Society.

\section{REFERENCES}

1. Global Initiative for Asthma. Global Strategy for Asthma Management and Prevention NHLBI/WHI Workshop Report Publication Number 95-3659. National Heart, Lung and Blood Institute, Bethesda, MD,1995.

2. Asthma Management Handdbook. National Asthma Council Australia, Melbourne, 2006. Available from: https://www.nationalasthma.org.au/healthprofessionals/australian-asthma-handbook.

3. British Thoracic Society and Scottish Intercollegiate Guidelines Network. British Guideline on the Management of Asthma: A National Clinical Guideline. British Society of and Scottish Intercollegiate Guidelines
Network, 2011. Available from: https://www.britthoracic.org.uk/standards-of-care/guidelines/btssignbritish-guideline-on-the-management-of-asthma/

4. Turktas H, Mungan D, Uysal MA, Oguzulgen K; Turkish Asthma Control Survey Study Group. Determinants of asthma control in tertiary level in Turkey: a crosssectional multicenter survey. J Asthma 2010; 47: 557-562.

5. Sekerel BE, Gemicioglu B, Soriano JB. Asthma insights and reality in Turkey (AIRET) study. Respir Med 2006; 100: 1850-1854.

6. Rabe KF1, Adachi M, Lai CK, et al. Worldwide severity and control of asthma in children and adults: the global asthma insights and reality surveys. J Allergy Clin Immunol 2004; 114: 40-47.

7. Kavut AB, Kalpaklıglu AF. Impact of asthma education meeting on asthma control level assessed by asthma control test. World Allergy Organ J 2010; 3: 6-8.

8. Kaya Z, Erkan F, Ozkan M, et al. Self-management plans for asthma control and predictors of patient compliance. J Asthma 2009; 46: 270-275.

9. Yilmaz A, Akkaya E. Evaluation of long-term efficacy of an asthma education program in an out-patient clinic. Respir Med 2002; 96: 519-524.

10. Bousquet J, Heinzerling L, Bachert C, et al. Practical guide to skin prick tests in allergy to aeroallergens. Allergy 2012; 67: 18-24.

11. Sekerel BE, Soyer OU, Keskin O, et al. The reliability and validity of Turkish version of Childhood Asthma Control Test. Qual Life Res 2012; 21: 685-690.

12. Uysal MA, Mungan D, Yorgancioglu A, et al. Turkish Asthma Control Test (TACT) Study Group. The validation of the Turkish version of Asthma Control Test. Qual Life Res 2013; 22: 1773-1779.

13. Wolf FM, Guevara JP, Grum CM, Clark NM, Cates CJ. Educational interventions for asthma in children. Cochrane Database Syst Rev 2003;(1):CD000326.

14. Cano-Garcinuno A, Diaz-Vazquez C, Carvajal-Uruena I, et al. Group Education on asthma for children and caregivers: a randomized, controlled trial addressing effects on morbidity and quality of life. J Investig Allergol Clin Immunol 2007; 17: 216-226.

15. Rastogi D, Madhok N, Kipperman S. Caregiver Asthma Knowledege Aptidute and Practice in High Healthcare Utilizing children: effect of an educational intervention. Pediatr Allergy Immunol Pulmonol 2013; 26: 128-139.

16. Wiecha JM, Adams WG, Rybin D, Rizzodepaoli M, Keller J, Clay JM. Evaluation of a web-based asthma self-management system: a randomised controlled pilot trial. BMC Pulm Med 2015; 15-17.

17. Tzeng LF, Chiang LC, Hsueh KC, Ma WF, Fu LS A preliminary study to evaluate a patient-centred asthma education program on parental control of home environment and asthma signs and symptoms in children with moderate-to-severe asthma. J Clin Nurs 2010; 19: 1424-1433.

18. Indinnimeo L, Bonci E, Capra L, et al. Clinical effects of a long-term educatioanl program for children with asthma- Aironet. A 1-yr randomized controlled trial. Pediatr Allergy Immunol 2009; 20: 654-659. 
19. Horner SD, Brown A, Brown SA, Rew DL. Enhancing asthma self-management in rural school-aged children: A randomized controlled trial. J Rural Health 2016; 32: $260-268$

20. Cerci Neto A, Ferreira Filho OF, Bueno T, Talhari MA. Reduction in the number of asthma-related hospital admissions after the implementation of a multidisciplinary asthma control program in the city of Londrina, Brazil. J Bras Pneumol 2008; 34: 639-645.

21. Koster ES, Wijga AH, Koppelman GH, et al. Uncontrolled asthma at age 8: the importance of parental perception towards medication. Pediatr Allergy Immunol 2011; 22: 462-468.
22. Yilmaz O, Eroglu N, Ozalp D, Yuksel H. Beliefs about medications in asthmatic children presenting to emergenecy department and their parents. J Asthma 2012; 49: 282-287.

23. Guenette L, Breton MC, Gregoire JP, et al. Effectiveness of an integrated care program on asthma control and adherence to inhaled corticosteroids. J Asthma 2015; 52: 638-645.

24. Ekici B, Cimete G. Effetcs of an asthma training and monitoring program on children's disease management and quality of life. Turk Thorac J 2015; 16: 158-165. 